\title{
AMÉRICA Y CERVANTES / EL QUIJOTE: EL CASO DE CHILE
}

\author{
Luis Correa-Díaz \\ University of Georgia \\ http://correa.myweb.uga.edu \\ correa@uga.edu
}

Si crees que todo cuanto has escuchado

no tiene contigo nada que ver,

estás amigo equivocado, párate a ver, párate a ver.

Mago de $\mathrm{Oz}^{1}$
¡Mientras perdure el Castellano en América aqui también ha de vivir Cervantes!
Antonio Batres Jáuregui ${ }^{2}$

El Quijote / Cervantes en Chile, en México, Colombia, Perú, Cuba, Ecuador, Argentina, etc.: una tarea pendiente desde que llegaron esos ejemplares de la novela a las en ese entonces llamadas Indias - cosa estudiada y documentada hace ya bastante tiempo por Francisco Rodríguez Marín, Irving Leonard y Francisco A. de Icaza, sin olvidar el antecedente legendario en Ricardo Palma. Una labor pendiente en su potencial mayor

1 "Ancha es Castilla" de La leyenda de La Mancha (2005). http://www.magodeoz.com

${ }^{2}$ Capítulo XX: "Miguel de Cervantes Saavedra en Goathemala". El castellano en América (1904), 275-285. El presente ensayo constituye una versión levemente ampliada de la introducción a 'El Quijote en Chile' de la antología El Quijote en América, que será publicada en-línea por el Centro Virtual Cervantes: http://cvc.cervantes.es/obref/ quijote_america/. Agradezco a Consuelo Triviño y al CVC en general su permiso para que mi trabajo aparezca en la Revista Chilena de Literatura. 
para llegar a superar los traumas coloniales de nuestra identidad, pero que a no dudarlo comenzó desde el mismo día en que se publicó El Quijote, porque éste traía en sí, pese a haber nacido en un mundo imperial y colonizador, la crítica de la 'razón de sus sinrazones' y es ése un legado entendido en América. El estudio y la ponderación, en sus múltiples sentidos y efectos, de esa salida transatlántica ha tenido sus paladines hasta hoy mismo - de allí, por ejemplo, que el proyecto del Centro Virtual Cervantes sea una feliz pantalla que hace visible la ya larga actividad crítico $\longleftrightarrow$ creativa en cuanto a la lectura americana y, a veces, americanista, por parte de las ex-colonias, corpus éste que en general ha sido silenciado, ignorado o, en el mejor de los casos, minimizado por la crítica canónica cervantista-, y los seguirá teniendo, puesto que a partir de las celebraciones del 2005 se puede decir, sin temor a equivocarse, que el campo de estudios denominado 'Cervantes y/en (las) América(s)' ha entrado en una etapa de autoafirmación y posicionamiento estratégico en los debates cervantinos ${ }^{3}$.

Este campo de estudios tendría que apoyarse, entre otras posibilidades que se han ido expresando, con una lentitud de siglos pero esperanzadoramente, en textos importantes de esta historia de Cervantes desde América, en los planteamiento teóricos de Walter Mignolo, formulados recientemente en su ensayo "De-linking: Don Quixote, Globalization and the Colonies" 4 . Estos corresponden a dos movimientos del ser y del saber (americano, para el caso) que terminan por aunarse: 'de-linking' y 'decolonizing', porque

To celebrate Don Quixote without bringing into the debate, simultaneously, the need to de-link and decolonize knowledge and being would contribute very little to the critical insights and dissenting arguments that Cervantes himself constructed through his master narrative (15).

Mignolo desarrolla con gran detalle las condiciones y proposiciones de esta lectura de El Quijote y el mundo vivido -y (des)escrito- por Cervantes, particularmente centrado

${ }^{3}$ Para todas las acotaciones al asunto del campo de estudios 'Cervantes y América", véase mi libro Cervantes y América / Cervantes en las Américas: mapa de campo y ensayo de bibliografia razonada (2006). [Tabla de contenidos en-línea: http://www.siglo-de-oro.eu/ html/7.html]. Además, Brioso Santos, Héctor [Con la colaboración de José Montero Reguera]. Cervantes y América (2006). Y para una entrada enciclopédica de reconocimiento: "Cervantes and America", en The Cervantes Encyclopedia (2004) de Howard Mancing, la que termina, además de consignar una bibliografía sumaria de apoyo, con estas palabras: "Furthermore, it has recently been suggested that a deep concern with America is a constant subtext that informs almost everything MC wrote, especially $D Q$ and Persiles" (Vol. I, 122-123).

${ }^{4}$ Véase, para una aproximación teórica general y comprehensiva de los estudios postcoloniales en América Latina, "Latin American postcolonial studies and global decolonization" de Fernando Coronil, en Lazarus, Neil, ed. The Cambridge Companion to Postcolonial Literary Studies (2004). 221-240. 
en el siglo XVII [y en la ejemplaridad de Waman Puma de Ayala ${ }^{5}$ y en el paradigma de coexistencia opuesto al de dominio; una lectura que "is not reducible to the hegemony of Western thought from Renaissance to today or anchored in Greece, Rome, and Jerusalem", lo cual atañe a una necesidad de toda geo-bio realidad colonizada:

... de-linking means to read Don Quixote, recognizing but not accepting the rules of the game in which Don Quixote was written and has mainly been read until today. De-linking means to admire Don Quixote as an outsider, playing a different game marked by a diversity of "experiences"-not the experience of the internal history of Europe, but those of the colonies where, for example, the primacy of alphabetic writing, the printing press, and the authority of colonial [imperial] languages were more of a problem than a victory $(10)$.

Una posición similar, aunque dentro de un marco disciplinario diferente, se puede ver en el ensayo "Don Quijote y los molinos de viento en América Latina" del sociólogo peruano Aníbal Quijano, quien remarca sus acotaciones así:

Es bueno, pues, que Don Quijote cabalgue de nuevo a desfacer entuertos, que nos ayude a deshacer el entuerto de la partida de toda nuestra historia: la trampa epistémica del eurocentrismo que desde hace 500 años deja en la sombra el gran entuerto de la colonialidad del poder y nos hace ver sólo gigantes, mientras los dominadores pueden tener el control y el uso exclusivo de nuestros molinos de viento $(6)^{6}$.

Esa es la tarea más general del lector de Cervantes/El Quijote desde América: una especie de letanía - a la manera de Rubén Darío- que se vuelve, una vez conjurada la derrota con el triunfo inexplicable (absurdo para el extranjero) de la propia dignidad, un ejercicio crítico (y creativo) que afirma para sí y demanda del otro el (reconocimiento del) derecho a la coexistencia, para solo así tornarse un día en un canto de amor al Nuevo Mundo, un "new space, the freeing and the clearing of coloniality of being that Waman Puma so masterfully blew up (and paid the price)"-como insiste Mignolo (7). Y esto porque ni la(s) Independencia(s), ni la Ilustración ni el Romanticismo del siglo XIX, tampoco los mejores empeños del XX, nos han liberado del todo de la falacia epistémica del que conquista, coloniza y crea un mundo de mestizos: la inferioridad.

5 "Waman Puma de Ayala introduced a spatial epistemic break and one of the first contributions to the politics of de-linking" (17).

${ }^{6}$ Aquí se podría traer a colación el artefacto de Nicanor Parra titulado "La diferencia entre él y yo": "180 x parte baja: / Yo me lanzo contra los molinos de viento / convencido de que son poderosos gigantes / En cambio él se lanza / contra poderosísimos gigantes / creyendo que se trata / de inofensivos molinos de viento". http://www.puntolatino.ch/literatura/ quijote7/?PHPSESSID=e3498177212153ca 530ffaebfcd06c8f 
Leer (y pensar) El Quijote -a Cervantes, la España/Europa de su tiempo y el nuestro- desde América en todos sus espacios, no únicamente el hispanoamericano, significa también, entre otras cosas, traerlo a estas tierras y sus ciudades ${ }^{7}$, como lo han hecho, entre otros, el ecuatoriano Juan Montalvo con sus Capítulos que se le olvidaron a Cervantes, el nicaragüense Rubén Darío con su cuento "D.Q.", el venezolano Tulio Febres Cordero con su novela Don Quijote en América, el boliviano Juan Francisco Bedregal con su extenso cuento fantástico "Don Quijote en la ciudad de La Paz", el guatemalteco Antonio Batres Jáuregui con su ensayo conjetural "Miguel de Cervantes Saavedra en Goathemala", el colombiano Pedro Gómez Valderrama con su cuento histórico "En un lugar de las Indias", la estadounidense Kathy Acker con su novela punk Don Quixote Which Was a Dream, el chicano Genaro González con su novela The Quixote Cult, la mexicana Angélica Muñiz-Huberman con su novela Dulcinea encantada, el uruguayo Eduardo Galeano con su micro-cuento histórico "1616, Madrid, Cervantes", el argentino Mempo Giardinelli con su crónica "El Quijote de Tres Lagos", el mexicano Alberto Blanco con su poema visual "La primera página", y el chileno Mario Olea se une a este elenco con su cuento fantástico-moral (incluso ecológico) "El regreso de Alonso Quijano, El Bueno". En esta fantasía conjetural le es concedido por el cielo a Don Alonso volver junto a Sancho a la tierra cinco siglos más tarde: "Un día, ya en el siglo veinte del planeta tierra, el Sumo Hacedor juzgó llegado el momento para el descenso de don Alonso y Sancho. Para no ser injusto, al azar, lo lanzó, cerrando sus ojos divinos, y vino a ocurrir que los viajeros aterrizaran en un país llamado Chile"; aventura angélica que termina con ambos personajes "esfumándose en los aires para nunca más volver y en la gloria del Señor quedarse por toda la eternidad" 8 . Al cuento de Olea se había adelantado, de cierta manera, Egidio Poblete [Ronquillo] con su crónica conjetural "El Quijote en Chile", de 1905, quien se pregunta, después de ironizar sobre los excesos discursivos relativos a las celebraciones locales del Tercer Centenario: “¿Qué haría Don Quijote si viniera al mundo en Chile y en los días que corren?" Luego de recorrer las tribulaciones de un número de hipótesis paródicosocio-políticas, concluye: "Don Quijote, pues, no podría vivir en nuestro país: se repetiría toda su primera vida. El único que puede hacerlo es Sancho Panza, su apellido le abría todas las puertas". Tanto Poblete como Olea plantean la misma decepción cervantina

${ }^{7}$ Recuérdese que Carlos Fuentes ha formulado con una precisión inigualable que "La Mancha, en verdad, adquirió todo su sentido en las Américas", El espejo enterrado (1992), 202-203.

${ }^{8}$ El regreso de Alonso Quijano. Cuentos-Reflexiones-Crónicas (2003), 43-60. Habría que considerar aquí los micro-cuentos actuales que trabajan recreando ciertas modalidades cervantino-quijotescas. Véase los chilenos Jorge Etcheverry, Juan Armando Epple, Diego Muñoz Valenzuela, Luis Correa-Díaz, Lilian Elphick, Lina Meruane y Pía Barros en MicroQuijotes (2005), editado por el especialista en micro-ficción Juan Armando Epple. 
respecto al impacto caballeresco (anacrónico) de Don Quijote en el mundo, tratándose aquí de una La Mancha americanizada, en un rincón apartado del Cono Sur. La diferencia se halla en que Pobrete no solo trae a los personajes al mundo chileno, sino que también reflexiona e introduce una crítica relacionada con la identidad hispanoamericana en cuanto a su herencia española: el triunfo del pancismo (en su aspecto negati$v^{9}$ ) por sobre el quijotismo; crítica identitaria y cultural que formulará más tarde, a través de un análisis histórico y caracterológico, el intelectual cubano Jorge Mañach en "El quijotismo y América", y que constituye uno de los apartados -quizás uno de los que más debate ocasiona- del campo de estudios a que me he referido más arriba ${ }^{10}$.

Junto a todos estos escritores que han escrito obras recreando, conjeturalmente, algún episodio o las aventuras completas de El Quijote (o la vida misma de Cervantes, como es el caso de Gómez Valderrama) en tierras americanas -relocalizándolas en lo cultural, en lo literario, en lo temporal, etc.-, están, por supuesto, los cervantistas americanos, tanto los de dedicación permanente al tema, como aquéllos que lo han hecho de manera ocasional pero iluminadora, quienes en conjunto han producido un corpus crítico considerable y que ha sido una contribución valiosa y original al cervantismo en general. Dentro de este extenso grupo se encuentran, por cierto, los cervantistas chilenos. De estos últimos he elegido, por las razones esbozadas, a los que en sus textos han incorporado una preocupación americanista en su lectura de la novela maestra, lo cual no significa dejar fuera a los que no han registrado 'el factor América' (usando la fórmula de Diana de Armas Wilson ${ }^{11}$ ) en sus trabajos, pero son una comarca que demandaría ser cartografiada y antologada de otra manera, al menos para las coordenadas que esta presentación del caso chileno se ha propuesto su autor. Para revisar un buen inventario de estos últimos hasta principios de la década de los setenta -lo cual implica, lógicamente, que sería necesario otro desde entonces hasta hoy-, y restringido a aquellos escritores vinculados a la Academia Chilena correspondiente de la Real Academia Española de la Lengua, basta ir al discurso "Académicos cervantistas" de Fidel Araneda Bravo, quien después de comentar con iluminadores detalles cada uno de los trabajos, acaba concluyendo el suyo con un párrafo que puede sonar pesimista, pero que si lo leemos solo circunscrito a su marco institucional no debería desalentar, pues lo cierto es que las letras chilenas en general muestran mayor prodigalidad de la esperada -aunque el comienzo haya sido dificultoso -como lo proponía Medina:

9 ... porque existe una mirada positiva al pancismo dentro de la posición americanista; siendo un ejemplo el cambio del Subcomandante Marcos, quien renuncia al modelo quijotesco y adopta el sanchesco. Se ha traído a Sancho también a juzgar la sociedad americana, particularmente su sistema jurídico, como lo hizo Julio Rozo Rozo con Sancho Panza. Gobernador y Juez frente a la legislación colombiana (1999). Véase Correa-Díaz 78-80 y 70-72, respectivamente.

${ }^{10}$ Capítulo de su Examen del quijotismo (1950), 152-162.

11 "The Americanist Cervantes". Cervantes, the Novel, and the New World (2000), 1941. 
He terminado el escrutinio de la Biblioteca Académica. Ahora sólo me resta dar excusas a mis colegas y demás oyentes, por no haber sido este examen tan donoso y exhaustivo como el que hicieran el cura y el barbero en la librería del ingenioso hidalgo; pero, al contrario de lo acaecido a mi cofrade Pero Pérez, el escrutinio de esta tarde no me fatigó, ni dio motivo tampoco para ordenar la quema de otros libros, porque en realidad la literatura chilena no es pródiga en obras dedicadas a Cervantes ${ }^{12}$.

De tal manera que para el caso que nos ocupa tendría que plantearse una problemática doble: a) ¿Qué lugar ocupa 'El Quijote en Chile' dentro del campo más amplio de estudios 'Cervantes y (las) América(s)'? - de esta pregunta se encargan los esfuerzos que han dado inicio a la antología particular del Centro Virtual Cervantes; b) ¿Qué lugar [del que los chilenos no quisimos acordarnos mucho en el $2005^{13}$ ] ocupa ' $E l$ Quijote en Chile', como reflexión americanista, dentro del cervantismo chileno? -para esta última cuestión, la selección presente pretende dar una respuesta inicial. La respuesta y constatación resultan sorpresivas y abundantes, y si llevamos los datos a la bibliografía general del campo la cantidad e importancia es comparativamente destacable, sobre todo si se piensa en el trabajo de Juan Uribe-Echevarría: Cervantes en las letras hispanoamericanas. Antología y crítica (1949), del que la antología presente muestra las secciones "Preámbulo" y "Primeros y últimos pasos de Don Quijote y Cervantes en América”.

Entonces, para empezar a finalizar esta introducción, habría que hacerlo por el principio, por José Toribio Medina, el cervantista mayor de entre los chilenos y uno de los más destacados que han sido en Hispanoamérica, y cuyos estudios sobre la vida y obra del español universal son referencia imprescindible. Medina escribió en 1923 su bibliográfica "Cervantes en las letras chilenas", que, como apunta Uribe-Echevarría en su detallado estudio sobre el maestro ("Medina cervantista. Antecedentes"), "rehace totalmente", corrige y aumenta, el trabajo que había adelantado en 1916 Leonardo Eliz: Apuntes para una bibliografia chilena sobre Cervantes en Chile. Según lo que cuenta Medina en su ensayo bibliográfico -y esto es importante para establecer una suerte de primera impresión respecto al tema Cervantes y El Quijote en Chile, refutada por él mismo, por los hallazgos encontrados, y que tendrán nuevas noticias de allí en delante por parte de otros estudiosos-: Chile es un país que, en apariencia, no tiene (tenía en ese entonces) mucho de cervantista, y, pese a la relativa popularidad que alcanzó El Quijote tempranamente en ciertas regiones de América (México, Perú),

${ }^{12}$ Incluido en El Quijote en Chile de Sergio Macías, 125-138.

${ }^{13}$ Salvo, claro está, de ciertas excepciones, ciertos comentarios y textos antologados en el volumen El Quijote en Chile (2005) de Sergio Macías; el breve artículo "El Quijote, ciudadano de América" de Carolina Pizarro Cortés, y Roberto Hozven con su ensayo "El Quijote, Cervantes y los ensayistas chilenos" (2005). El ensayo de Hozven podría considerarse como la punta del iceberg de un paradigma mayor por investigar. 
"tenemos las pruebas de que nunca se leyó la obra de Cervantes en Chile antes de los últimos años del siglo XVIII", debido en gran medida a sus particulares circunstancias histórico-socio-geográficas, tanto durante la Colonia como en los alrededores de la Independencia (568). Poco a poco empezarán a aparecer ejemplares importados en bibliotecas privadas, aunque tampoco la suerte cambió significativamente durante los inicios del siglo XIX. Es solo a partir de mediados del XIX que se multiplican en número menor a la decena los ejemplares registrados por libreros. Según lo que apunta Medina, la primera edición local sería una abreviada, impresa por el librero español don Santos Tornero en 1863 en Valparaíso. Agrega Medina en los párrafos introductorios a su catálogo: "Así, pues, sólo a partir de tal fecha logra el investigador ir anotando uno que otro título referente a Cervantes" (569); siendo desde ahí (1878) en adelante las fechas recordatoria del nacimiento o de la muerte de Cervantes y celebratorias de la aparición de El Quijote -hasta la más reciente del 2005- los hitos que irán dando forma a lo más visible del cervantismo chileno, sin olvidar, por cierto, que entre tales fechas Chile ha producido un corpus crítico y creativo notable. Ejemplos mayores de lo uno y de lo otro son Don Quijote y la poética de la novela (1992) de Félix Martínez Bonati, y el poema "Don Quijote impugna a los comentadores de Cervantes por razones puramente personales" (1975) de Pedro Lastra ${ }^{14}$.

El "Cervantes y las letras chilenas" de Medina, que completaba al de Eliz, es un semillero continuado por otros investigadores, aunque su propuesta de fondo, la invitación a acopiar y anotar un tipo de repertorio completo, nunca se ha emprendido a cabalidad después de él. Sin embargo, en esta línea está el "Cervantes en Chile” (1947) de Julio Molina, quien termina sus comentarios y aporte de referencias con un párrafo bastante borgiano:

La materialidad de ciertas acciones guarda nada más que apariencias, podrán alegar los que conciben la narración del pasado como un constante juicio de pruebas. Pero no olvidemos que el objeto de la ciencia literaria son las ficciones mejor concebidas. Cuando estas ficciones o novelas cumplen su fin más edificante, es que ha sonado la hora de preguntarnos acerca de si no será sólo por ellas mismas que nosotros estamos contando la historia de su argumento o practicando los ritos aconsejados por sus singulares invenciones (147).

En la misma línea de catálogo bibliográfico se encuentran las páginas "La influencia de Cervantes y de su obra en Chile" (1952) de Maurice W. Sullivan. Este investigador tiene el mérito de catalogar el material recopilado (reconociendo los trabajos anteriores de Eliz, Medina, Molina y Uribe-Echevarría), estableciendo "los siguientes apartados,

\footnotetext{
${ }^{14}$ Mencionarse merece una de las últimas publicaciones chilenas que estudian y guían la travesía del lector de la obra de Cervantes: Para leer El Quijote (2000) de Lucía Irma Césped Benítez.
} 
correspondientes a diversas formas de manifestarse la influencia cervantina: Obras directamente imitadas o inspiradas por Cervantes; Obras en que puede advertirse filiación cervantina; Poemas dedicados a Cervantes, su obra o sus personajes; Estudios críticos, y Conmemoraciones" (291). Esfuerzo similar había realizado Uribe-Echevarría, pero extendido a toda Hispanoamérica. Dentro del apartado "Estudios críticos cerrvantinos", Sullivan crea el importante subapartado "Chilenos en la ruta de Don Quijote" -el que sería necesario extender a toda América-, donde se halla una serie de escritores pertenecientes al canon nacional: Benjamín Vicuña Mackenna con sus "impresiones" tituladas En La Mancha (1878), Rafael Sanhueza Lizardi con su Viaje a España (1886) y Augusto D'Halmar, el más completo de todos en este sentido, con su La Mancha de Don Quijote (1934). Carlos Sander en el capítulo "América y los molinos del Quijote" de su libro En busca del Quijote (1967), el que evidentemente no podía conocer Sullivan al momento de publicar su estudio, ejecuta una operación radical y que lo coloca necesariamente dentro del posicionamiento americanista del campo de estudios que se ha descrito, aunque el poeta apela a un reencuentro entre España y América, donde aquélla vería a sus ex colonias no como hijas sino como hermanas -"por la madurez política, social, cultural y moral que ya tienen" (310). Cito en extenso la propuesta de Sander que por sí misma es quizás la más audaz de las que se han hecho hasta la fecha $-\mathrm{y}$ por supuesto, se mantiene en estado de ideal irrealizado-, además de haberse adelantado en décadas a los trabajos de España por crear definitivamente la "ruta de Don Quijote":

Les expreso [a los habitantes y autoridades de Campo de Criptana] que América tiene una deuda de gratitud con el príncipe de la lengua castellana, Don Miguel de Cervantes Saavedra, que hizo conocer de manera magistral el idioma más cantarino y hermoso de la tierra. Que esa deuda de gratitud debe pagarla, en moneda buena y bella, moneda espiritual e intelectual. Debe perpetuar en un escenario como Campo de Criptana, su amor a España, la madre ubérrima y fundadora. Hay que cumplir todos los ideales enunciados por los que luchan por reconstruir los viejos molinos en diversos pueblos de la Mancha. Especialmente Campo de Criptana, la ciudad de los molinos, debe reconstruirlos y planteo la idea. América debe ser la que reconstruya los molinos del Quijote. Cada país debe reconstruir su propio molino. Que llevará uno de los nombres de los viejos molinos, que figuran en el Catastro del Marqués de la Ensenada y que fueron los que Cervantes vio cuando vino a este pueblo. Los molinos reconstruidos por los países americanos, no tendrán en su interior maquinarias que muelan trigo y produzcan harina. Estarán divididos en dos plantas, comunicadas entre sí por una pequeña escalera. En esas plantas se colocará un museo artístico e intelectual del país que lo reconstruya. Cuando los veintidós países del otro lado del mar hayan reconstruido los molinos e instalado los museos que se proyectan, el Estado español trazará en forma seria la ruta del Quijote que pasará a través de todos los pueblos cervantinos que figuran en el libro inmortal y construirá hoteles y paradores a lo largo de la ruta, ya que cientos y miles de gentes llegarían a bañar su alma, a purificar su espíritu en los pueblos cervantinos y especialmente a mirar en Campo 
de Criptana a los veintidós molinos de América. Podrán entonces conocer en forma detallada lo que somos en el mundo intelectual y artístico, va que cada país mostrará en "su molino" lo que es, exhibiendo con orgullo su museo. Así las gentes venidas de todo el mundo, del Oriente y Occidente, conocerán en forma bastante completa a nuestra América, que estará presente en el corazón de la Mancha (311-312).

Otros ensayos que deberían figurar en un apartado especial en lo que Sullivan denominó "Estudios críticos cervantinos", son los que están relacionados con la influencia de El Quijote y su lengua en la de Chile y, ampliando el marco, en su folklore. En esta línea están, cronológicamente, los trabajos Cervantes en el folklore chileno (1915) de Clemente Barahona Vega, "La lengua del Quijote y la de Chile" (1916) de M. Antonio Román -ambos citados por Sullivan-, y "El Quijote y nuestro lenguaje" (1959) de Pedro Lira Urquieta. Asimismo se tendría que agregar un apartado dedicado a la crítica literaria sobre las obras de escritores americanos que manifiestan influencia cervantina y, más específicamente, sobre la de aquéllos que han recreado, episódica o extensamente, El Quijote. De estas escrituras se ha seleccionado el estudio "Juan Montalvo: una reescritura del Quijote en América" (1998) de Marcela Ochoa Shipavour ${ }^{15}$.

Para concluir con estas referencias a los inventarios comentados que recogen el material cervantista en las letras chilenas, hay que hacerlo con el último y que vino en la forma de antología de carácter misceláneo: El Quijote en Chile (Santiago: Aguilar, 2005), selección, notas e introducción del escritor Sergio Macías, quien en ésta última, titulada "De cómo el Ingenioso Hidalgo Don Quijote de La Mancha llegó a Chile", tiene el acierto de comenzar - a la manera de Medina y otros, en cuanto a sus esfuerzos de pesquisar la presencia de América en la obra cervantina- así: "Chile aparece en El Quijote a través de la famosa obra La Araucana, cuyo autor es el soldado y poeta nacido en Madrid, pero de sangre vasca, Alonso de Ercilla". Para luego comentar haciendo un contraste interesante si acordamos aceptar lo que proponen algunos destacados cervantistas, que Cervantes no necesariamente comulgaba con el imperio en todo:

Ercilla, que luchó de voluntario en la conquista de Chile, se convierte en personaje y, como don Quijote, está convencido de que su contienda tiene como finalidad un mundo mejor, sin que presente, claro está, ningún síntoma de locura y su idealismo pueda ser muy discutible. Creía en la política

${ }^{15}$ El texto de Ochoa Shipavour forma parte de su libro Reescrituras del Quijote (1997). Para una extensión de estos apartados al ámbito americano en general, véase Correa-Díaz 37 y 55-69, respectivamente. La antología presente incluye dos textos que podrían pertenecer a un apartado especial: 'testimonio personal de influencia' por parte de escritores y artistas. Así son de interés los discursos de recepción chilenos del Premio Cervantes: Jorge Edward (1999) y Gonzalo Rojas (2003). 
del imperio. Tampoco llega a ser, por otro lado, un Sancho Panza. Ercilla es partícipe y testigo de la guerra contra los araucanos; Cervantes, en cambio, inventa el personaje que está inmerso en los sucesos propios de su mundo ficticio $(13-14)^{16}$.

Después de sintetizar que tanto Don Quijote como Sancho "se integran como personajes de la cultura nacional" (17), situación propiciada, en su gran mayoría, por la institucionalidad educacional y por la persistencia de los escritores y otros agentes culturales en referirse, individual y colectivamente, a la importancia de la obra de Cervantes, en lo relativo a la lengua y a otras áreas de la vida chilena, Macías describe brevemente lo que es hoy la ruta de Don Quijote y cuenta un hecho que habría alegrado sobremanera a Sander:

Aparte de tres molinos antiguos que aún se conservan, los otros han sido reconstruidos. Entre estos últimos uno lleva el nombre del gran poeta chileno, fundador del creacionismo, Vicente Huidobro. La Embajada de Chile en España tuvo una destacada actuación para que esto se concretara, y actualmente el molino Huidobro es parte del complejo turístico cultural de Campo de Criptana. En este molino se podrán encontrar libros donados por la embajada y un par de carteles en los que figura un poema de Huidobro creado a semejanza arquitectónica de un molino $(21)^{17}$.

${ }^{16}$ Para un estudio acabado, véase el ensayo de Diana de Armas Wilson “'De gracia estraña': Cervantes, Ercilla y el Nuevo Mundo" (1999). También el de Isaías Lerner, "América y la poesía épica áurea: la versión de Ercilla" (1991). Pese a todo esto, no hay que olvidar lo que Gilberto Triviños advierte en su ensayo "La hermosa y decisiva conquista de la Araucanía" (2003) respecto a las vicisitudes del poema de Ercilla como epopeya fundadora de la 'nación chilena': "La Araucana no es realmente nuestro libro nacional. O sólo lo es cuando silenciamos, como ostentosamente sucede en la Crónica de la Araucanía" de Horacio Lara, publicada en 1889. Crónica que, como lo propone Triviños, es "una borradura antiercillesca de la violencia del origen de Chile como nación moderna"; ya no es el canto (humanista) al pueblo mapuche sino a los héroes (militares y la sociedad chilena) de la Pacificación de la Araucanía”. Por eso es que si de reconocer a corazón abierto se tratara: "El país surgido de la llamada pacificación debe al 'talento y patriotismo' de Lara mucho más que la memoria de las épocas gloriosas de la Araucanía” (239-251).

${ }^{17}$ Quizás sea oportuno traer a texto aquí una anécdota similar pero en dirección contraria y que atañe más bien a la relación entre los cervantistas peninsulares y los americanos (cosa que podríamos entender, de todos modos, como el tramo transatlántico de una ruta intercontinental de ida y vuelta). El uruguayo José G. Añunta apunta, entusiasmado, en su ensayo Cervantes y el Quijote en tierras de América (1960): “Cervantistas, a través de los siglos, se han abrazado en el culto común con los cervantistas de América. Se confundieron en el pensamiento y en el sentir hispanos, emoción y pensamiento que en gesto de hermosa hidalguía quiso cristalizar don Jaime Morales de Pantoja, Presidente de la Sociedad Cervantina y alcalde de El Toboso. Eso fué cuando envió desde este mismo pueblo, en 
Macías concluye, recordando a Araneda Bravo, Román y al folklorista Ramón A. Laval, insistiendo en la idea del poder que ha tenido El Quijote en la formación nacional de Chile, particularmente entre sus académicos, escritores y en muchos aspectos de "nuestro lenguaje popular", citando a Lira Urquieta para ejemplo de esto último: "el habla chilena del pueblo "está más cerca del lenguaje cervantino de lo que pudiera imaginarse"" $(23)^{18}$. Afirmación que, evidentemente, habría que revisar ya en esta primera década del siglo XXI, pero que a mediados del XX era válida, como lo probara Lira Urquieta. Los autores seleccionados por Macías son: Amanda Labarca, José Toribio Medina, Augusto D’Halmar, Luis Durand, Juan Uribe-Echevarría, Fernando Santiván, Armando Uribe, Fidel Araneda Bravo, Pedro Lastra, Enrique Krauss, Alfonso Calderón, [Roberto] Matta, Cristián Vila, Luis Rubilar, Ambrosio Rabanales, Sergio Peña y Lillo, Jorge Edwards, Carla Cordua, Mario Rossel, Gonzalo Rojas, Félix Martínez Bonati y Teresa Calderón. Algunos de estos nombres figuran en la presente antología del Centro Virtual Cervantes. Repito, los textos de aquellos que incorporan el "factor América" en sus reflexiones.

Todos estos estudiosos mencionados hasta aquí no se restringen en sus observaciones solo a la cuestión Quijote $<>$ Chile, sino que además no vacilan en extender sus conocimientos y comentarios de determinados aspectos, históricos o interpretativos, al campo 'Cervantes y América" -o de las Américas y Cervantes. Así, el caso de Molina, el que, por ejemplo, tiene algunas líneas que ya estaban en la órbita de lo planteado por Mignolo -aunque sin apartarse del todo del sistema epistemológico europeo según los conceptos de este último-, y en lo que hoy entenderíamos por globalización de la literatura:

Acostumbrados a considerar que la literatura universal es, por un egocentrismo históricamente explicable, aquella de los países de Europa, se nos hace difícil aceptar cuando recordamos el carácter ecuménico de la obra de Miguel de Cervantes, el de una chilenidad en las proyecciones superiores de las mismas. No es que deseemos colocar nuestro caso particular en un terreno arbitrario, siguiendo los movimientos tardíos del amor hacia España; pero la verdad es, para todos los que buscamos adentrarnos en su

1938, un mensaje de hermosa elocuencia dirigido a los Cervantistas de América: un puñado de tierra de El Toboso y una astilla de la puerta del palacio de Dulcinea" (11).

${ }^{18}$ En cuanto a las vicisitudes por las que ha pasado El Quijote en la historia de la vida nacional chilena, habría que dejar constancia también de lo que Alberto Manguel ejemplifica anecdóticamente para su capítulo "Forbidden Reading" de su A History of Reading (1996): "Comstock's methods were savage but superficial. He lacked the perception and patience of more sophisticated censors, who will mine a text with excruciating care in search of buried messages. In 1981, for instance, the military junta led by General Pinochet banned Don Quixote in Chile, because the general believed (quite rightly) that it contained a plea for individual freedom and an attack on conventional authority" (286). 
invencible simpatía, que algún papel puede tener para los que gusten oírnos este punto de vista. El hispanismo del ánimo admirativo pudo servir a los hombres de afición literaria en algún recodo del sendero, más hoy en que las voces especializadas nos dicen que una obra literaria hace su estreno en la literatura de todas las épocas y regiones desde el momento en que no pertenece a la literatura de un determinado continente, todo ello es susceptible de no seguir siendo considerado tan absurdo $(137-138)^{19}$.

O el caso de Sullivan, quien comienza su estudio con una sección introductoria, "Cervantes y El Quijote en América", donde su primer párrafo establece el marco más general de sus consideraciones sobre la influencia cervantina en Chile:

El estudio de la llegada, la influencia y el aprecio de la obra de Cervantes en Chile no es más que una parte del estudio de los mismos temas en toda la América hispana, dada la comunidad de influencia literaria durante toda la época colonial. Sin embargo, siempre se pueden señalar algunas diferencias o particularidades (19).

Lo mismo queda patente también a partir del título con el libro de Uribe-Echevarría, Cervantes en las letras hispanoamericanas (1949). En el "Preámbulo", su autor precisa sin vacilaciones, después de ponderar la buena fortuna (globalizada) de El Quijote fuera de España (recordando unas páginas del crítico Omer Emeth), que "[a]sí y todo hay un Cervantes privativo del mundo hispánico", subsumiendo el hispanoamericano - $\mathrm{O}$ americano a secas- en el anterior, pero distinguiéndolo de manera notoria con su propio trabajo. De modo que podríamos afirmar que hay un Cervantes y un Quijote "privativo" del mundo americano desde que llegaron esos primeros ejemplares e iniciaron una historia de lectura e interpretación desde/en y, sobretodo, para el continente. Desde su posición temporal, de mediados del siglo xx, Uribe-Echevarría, con una tradición ya establecida y con un futuro auspicioso, reconocía: "Estas manifestaciones de fervor cervantino se producen también en América desde mediados del siglo pasado y en marcha tan ascendente como en la propia España" (12). Manifestaciones que, indica, no solo están restringidas al mundo académico:

Desde hace un siglo o más, Cervantes es en América tema escolar de colegios secundarios y universitarios. También es referencia periodística y frase de discursos políticos, patrióticos o simplemente familiares. Pero también, y esto es lo que importa, una influencia moral y literaria de Cervantes

${ }^{19}$ Planteamiento parecido surge, un tiempo después, en el ensayo del uruguayo Añunta y que tiene el mérito de hacer una crítica al excesivo nacionalismo crítico: "Enorme orquestación universal ha desatado la obra cervantina. Durante cuatro siglos ha sido incontenible su internacionalismo, a pesar de los motivos centrales que le atribuyeron la fortaleza nacionalista de los manuales. Cervantes mismo, caballero andante del mundo, fué, esencialmente, un espíritu internacional y del más vasto itinerario" (15). 
y el Quijote se ha ejercitado en gran cantidad de hombres representativos del pensamiento americano. Críticos, poetas, novelistas, ensayistas, dramaturgos y reformadores sociales y políticos han hurgado con desigual éxito y tesón en la vida y en la obra del escritor complutense (15).

El libro de Uribe-Echevarría y su en apariencia sencillo propósito -"Nuestra labor se ha reducido a recoger las noticias más seguras sobre el conocimiento que se tenía en América de la obra cervantina en los siglos XVII y XVIII, y a verificar su influencia variable pero constante en el arte y el pensamiento hispanoamericanos a partir del siglo XIX" (15)- es, junto con los trabajos de los mexicanos Rafael Heliodoro Valle y Emilia Romero ${ }^{20}$ y el ya aludido de Correa-Díaz (aunque éste tiene un enfoque más especializado en lo americanista, como se ha dicho), la fuente de este proyecto bibliográfico mayor que incluye los diversos rincones del continente, y que por cierto se nutren de la labor realizada por los investigadores de cada país, como el trabajo de Medina y otros sobre el asunto cervantino en las letras chilenas.

Podría decirse que una de las particularidades que Sullivan planteaba como hipótesis, y que aquí propongo para el caso chileno, entre otros (como México, Colombia, Perú, por ejemplo), sería ésta de contar con una relativa abundancia y persistencia de textos que vinculan el asunto América con Cervantes, El Quijote y las demás obras suyas. Por eso, volviendo a Medina, quien fue el primero en hacerlo en el continente (al menos hasta donde llegan mis conocimientos a la fecha ${ }^{21}$ ), su contribución no fue solo en relación con el Quijote en Chile, sino también al campo más amplio del cervantismo americanista, con su discurso leído en 1916, en el tercer centenario de la muerte de Cervantes, ante la Academia Chilena de la Lengua: "Cervantes americanista: lo que dijo de los hombres y cosas de América"22. Y es esto lo que lo convierte en un factor fundamental para el campo de estudios y es lo mismo que Uribe-Echevarría se encarga de destacar en su trabajo sobre el gran investigador de las letras americanas ${ }^{23}$. También lo haría, décadas más tarde, Diana de Armas Wilson en su capítulo homónimo

${ }^{20}$ Bibliografía cervantina en la América Española. México (1950).

${ }^{21}$ La noticia más temprana con la que cuento es peninsular: Apráiz y Sáenz del Burgo, Julián de. "Cervantes y América." Sawa, Miguel y Pablo Becerra, eds. Crónica del Centenario del "Don Quijote (1905), 314-317.

${ }^{22}$ Medina escribió además en 1926 un estudio titulado "Escritores americanos celebrados por Cervantes en el Canto a Calíope".

${ }^{23}$ José Montero Reguera, en su ensayo "El Quijote en Hispanoamérica", comenta sobre esto de la manera siguiente: "La obra cervantina de José Toribio Medina significa la culminación de la crítica chilena sobre Cervantes, a través de un nutrido número de trabajos que, con palabras de Federico de Onís 'añaden, no sólo gran caudal de datos nuevos, sino una interpretación original de Cervantes al ser mirados desde puntos de vista americanos"” (Brioso Santos 325). Y Añunta comentaba que tanto Medina como Uribe-Echevarría "se destacan de la nutrida legión para señalar la presencia de Cervantes americanista" (20). 
"The Americanist Cervantes", quien atestigua la deuda con el chileno por este título, y se plantea allí y, en gran medida, en el resto de su importante libro, ir desde los inventarios originales - como el de Medina, y también el de Jorge Campos (Revista de Indias 8 (1947: 371-404)- a los esfuerzos interpretativos (28-30), contribuyendo de tal manera al reconocimiento y a la proyección definitiva de esos primeros trabajos fundadores de la sección "Presencia de América en la obra de Cervantes" del campo 'Cervantes y América' ${ }^{24}$ ".

En esta línea de investigaciones cabe incluir los textos aquí seleccionados de los chilenos que han abordado el tema con posterioridad: a) "América y Cervantes" (1947) de Luis Durand, texto que fue la editorial de ese número especial de la revista Atenea en que se festejaban los cuatrocientos años del natalicio de Cervantes, y como tal, creo, desde la perspectiva del tiempo transcurrido, fue emblemático de una cierta posición, ciertamente 'criolla' - como la que se representa quizás con más claridad en el ensayo ya mencionado del uruguayo Añunta $-{ }^{25}$, es decir, que reflejaba todavía un cierto grado de subalternidad, pero que ya contiene un decidido reclamo en la participación que le corresponde en el patrimonio de la herencia cervantina: no solo se trata de registrar la presencia de América en la vida y obra del soldado-escritor como una dato filológico e historiográfico-literario, sino que de ver cómo América ha leído y recreado desde entonces su propia historia en contraste con tal vida, obra, idioma y época; b) "Presencia de América en la obra de Cervantes" (1947) de Jorge Fernández, donde se sostiene con precisión sumaria, a partir de la consideración del fracasado intento de Cervantes de pasar a las Indias, que:

Quizá por ello su obra se va llenando cada vez más con la reminiscencia hacia el puesto no alcanzado. Hemos podido advertir ya que las citas alusivas al Nuevo Mundo, aumentan a medida que nos ocupamos de producciones posteriores. Si en La Galatea, por su condición pastoril no aparece la cita, abunda en el Quijote y las Novelas Ejemplares y se acentúa en la Segunda Parte del Quijote, las Comedias y los Entremeses, hasta llegar al Persiles en que el recuerdo americano es esencial (200),

${ }^{24}$ Véase Correa-Díaz 23-29.

${ }^{25}$ La lectura de El Quijote en América ha sido siempre criolla (al principio indiana, por supuesto), en su más amplio sentido, mestiza (tanto de élite, de clase media, como popular), si se quiere, a partir de algún determinado momento, pero nunca indígena. ¿Existe/ existiría un Quijote para el mundo indígena? Bueno, ahora sí con la traducción al quechua (o sea al runa simipi = en quechua, en el lenguaje imperial) de El Quijote / Yachay Sapa Wiraqucha Dun Qvixote Manchaymantan, hecha por el teólogo y periodista Demetrio Túpac Yupanqui, publicada por la Empresa Editora El Comercio de Lima en el 2005 y presentada en la Feria Internacional del Libro de Guadalajara, México, en noviembre de ese año. Sabemos, también, que ya La Araucana [Ta Awkan Mapu Mew] de Ercilla, en versión bilingüe -traducida recientemente al mapudungún por Manuel Manquepi, adaptación poética del poeta mapuche Elicura Chihuailaf-, puede estudiársela en esa relación. 
lo que lleva a Fernández, quien tiene el mérito de prestar más atención que otros al asunto de cómo se registra la presencia indígena americana en la obra cervantina, su ensayo con el siguiente párrafo:

He aquí, pues, a América presente a lo largo de toda la obra cervantina. No como una preocupación literaria, si no como parte integrante del mundo real a que acudía para elaborar su ficción. Las tierras de indias citadas a cada paso, las costumbres de sus naturales tenidas en cuenta, y germen indudable de su última producción. América así no es ajena a la creación novelística del genial español (205);

y, finalmente, c) la conferencia "Imagen fabulosa de las Indias a través de Cervantes" (1992) de Adriana Arriagada de Lassel, quien, siguiendo un derrotero ya tradicional de acudir a una especie de inventario de "alusiones", pone el acento, como el mismo título lo señala, en el carácter fabuloso, mágico, exótico, utópico, mítico de esa presencia de América; sin embargo, Arriagada de Lassel parece ser más reservada que los investigadores anteriores:

Para Cervantes, las Indias era parte integrante del mundo nacional español. Normal, por lo demás. Esto era así para cualquier peninsular de su época.

En conclusión, América existió en la obra y la vida del máximo escritor de nuestra lengua, pero la América de Cervantes es la visión lejana, exótica y hegemónica del español común de sus tiempos.

Cervantes, absorbido quizás por la realidad española y mediterránea, vio a América más como un lugar ideal, maravilloso o terrible que como el real continente que era $(18)^{26}$,

lo cual resulta comparativamente estimulante, toda vez que se trata hasta hoy de un área en disputa, no en lo que toca a la realidad y extensión de las referencias en Cervantes, sino más bien en cuanto a cómo interpretarlas, qué función cumplen en la obra del Alcalaíno universal, y de qué modo éstas lo situarían a él en el contexto de la aparición

${ }^{26}$ Uno de los subapartados de la sección "Crítica literaria" en torno a los escritores de las Américas y El Quijote es aquél que aborda el tema del 'realismo mágico’ y sus congéneres entre ambos. Ejemplo de esto es el ensayo "The Quixotic Roots of Magic Realism: History and Fiction from Alejo Carpentier to Gabriel García Márquez" de Edwin Williamson, Edwin en Cervantes and the modernists: the question of influence (1994). El discurso de recepción del Premio Cervantes de Jorge Edwards, "La aventura del idioma" (1999), contiene esta declaración del novelista chileno: "Para mí, el gran realismo mágico de la literatura en lengua española, el de una fantasía superior, es el de la segunda parte del Quijote, el de la Cueva de Montesinos, el de Clavileño, el del Caballero de los Espejos. El maravilloso desfile de la imaginación medieval en el interior de la cueva de Montesinos anuncia el desfile del mundo moderno en el Aleph de Jorge Luis Borges” (Macías 220). 
de América en la mentalidad europea y viceversa. Mi postura personal -si es pertinente dejarla expresa aquí- se acerca más a la de Fernández.

De todos modos, ninguno de estos textos, tampoco el de Medina, llegaron -no podían hacerlo dado el contexto cultural en que están inmersos (con la excepción de Arriagada de Lassel, que es de 1992, pues, como se sabe, ésa ya era una fecha propicia para intentar una aproximación más americanista al tema)- a establecer posiciones como la que se ha ejemplificado, al principio de esta introducción, a través de Mignolo, situación que evidentemente no tiene por qué llevar a descartarlos; no habían alcanzado el estadio crítico de una existencia epistemológica independizada (que busca coexistir), pero constituyen el basamento documental de un campo de acción intelectual que se ha venido desarrollando tanto en Chile como en los demás lugares de América.

Por último, quisiera referirme al ensayo "América, meta de la caballería" (1945) de Jaime Eyzaguirre, donde su autor presenta un concepto, el de "Don Quijote transplantado", que es fundamental dentro de una sección muy definida, "El quijotismo en el Descubrimiento y Conquista/Evangelización de América", dentro del campo 'Cervantes y las América' (Correa-Díaz 72-77). En este apartado se aborda el asunto del quijotismo de los conquistadores y evangelizadores (ecuación que, por cierto, es material abierto a la discusión), de lo que Diana de Armas Wilson conceptualiza como "el despliegue de cualidades quijotescas mucho antes de que lo hiciera el propio Don Quijote" 27 . Eyzaguirre, ya a mediados del siglo xx, pasaba revista a esto -el valor y otras virtudes caballerescas en los hombres principales venidos a las Indias-, ciertamente de manera apologética - más moderada, no obstante, que la que se encuentra en el ensayo de Añunta- (y que otros historiadores justamente han corregido, en especial desde la perspectiva/voz del vencido ${ }^{28}$ ), aunque su intención es entregar una visión ecuánime, dentro de sus propios parámetros culturales, que muestre que, al menos en el caso del Reino de Chile (el "Flandes indiano" por su resistencia prolongada y tenaz frente al invasor), hubo un reconocimiento de igualdad hacia el indígena (el, en ese entonces, araucano) por parte de aquéllos que llevaron a esas lejanas latitudes sus empresas militares y religiosas:

27 "Cervantes and the New World" en The Cambriedge Companion to Cervantes (2002), 206-225. Véase también su subcapítulo "The 'Quixotic' Conquistadors" en el libro ya mencionado Cervantes. The Novel, and the New World (2000), 113-116.

28 "Sus relatos [de los mapuches] fragmentarios, orales, olvidados, irrumpen insolentes en el espacio de la historia de Bengoa para decir lo que 'no se puede negar ni ocultar', para recordar lo impensable en los grandes discursos historiográficos, todos ellos del tipo romano, de Vicuña Mackenna, Amunátegui, Barros Arana, Errázuriz, Lara y Lobos: la hermosa historia de la conquista de la Araucanía es sólo la historia negra de un exterminio" (246), y para el pacificador (la nación chilena) un hito fundamental en el camino del desarrollo y de la consolidación de la "riqueza privada y pública" al apropiarse de las tierras de la Araucanía. 
Por eso será en Chile donde se extinguirá más tardíamente que en ningún otro lugar el espíritu caballeresco y donde aun en pleno siglo XVII serán valederos ciertos padrones del espíritu que se han tornado ineficaces en el resto de América y, sobre todo, en Europa.

Cuando ya en España el Quijote aparece vencido por el pícaro, y un desaliento colectivo sucede a la inspirada tarea del siglo anterior; cuando comienza a dudarse de los ideales por que se ha combatido y un desgarramiento y escepticismo interiores abren las puertas a la decadencia, en Chile los postulados de Francisco de Vitoria tienen en el Padre Luis de Valencia un denodado vocero y se ensaya con empeño el sistema de la guerra defensiva. Todavía en esta tierra hay quienes piensan en la posibilidad de subordinar a principios de derecho una lucha que se va haciendo centenaria. Y cuando la noble intención parece del todo derrumbada, sobrevive la sustancia en el sistema de los parlamentos de Arauco, donde españoles e indios periódicamente reajustan las leyes de la guerra y las normas de la paz. Acaso hubo margen entre lo obtenido y lo anhelando, pero no es poca cosa que un país conquistador llegue a otorgar tratamiento de igual a un pueblo de salvajes (sic). En esos históricos parlamentos, los convenios se celebraron de potencia a potencia, entre el Reino de Chile y el Estado de Arauco como regidos por el derecho internacional que supo llevar al campo público la suprema creencia de la raza en la igualdad esencial de los hombres.

España, que se había paseado sin obstáculos de mar a mar y había cogido medio globo en el puño, sólo vino a saber lo que era hallar resistencia en las llanuras de Flandes y en las selvas de Arauco (sic). Por eso un escritor del siglo XVII, el Padre Diego de Rosales, quiso hacernos pasar a la historia como tierra de detención de la más grande potencia del mundo y llamó a nuestra patria Flandes Indiano, nombre que habla mucho de hazañas, pero también de grandes desalientos para la caballería $(12)^{29}$.

El escritor Darío Oses dedica una continuación de su crónica en-línea "Quijotes y quijotadas en la historia de Chile" (2005) a "El Quijote de la paz", quien no es sino el padre Luis de Valdivia, a quien le cupo lugar, "contra los molinos de los intereses" económicos y militares de ambos bandos, en lo que se suele llamar, eufemísticamente, la Pacificación de la Araucanía. Oses vuelve a recordarnos que el padre Valdivia pertenece de suyo a "la estirpe de Bartolomé de Las Casas, de Vasco de Quiroga [otros Quijotes, como consta en el material bibliográfico existente al respecto para el campo de estudios] y de muchos otros españoles que buscaron imponer en América los valores de

${ }^{29}$ De acuerdo a Jacques Lafaye en el capítulo tercero, "Los medios de la conquista", de su Los conquistadores (1999), argumenta, en este sentido, que "América se convirtió en el refugio de los señores feudales a la antigua, en el último escenario de las hazañas de la caballería tradicional. No es muy seguro que en Don Quijote no haya más nostalgia que ironía" (37). 
la cristiandad y construir una sociedad de europeos, indígenas y mestizos viviendo en armonía" (1).

Lógicamente, reitero, estos tipos de comentarios, si bien hacen suya la figura identitaria de Don Quijote para los hombres y las cosas de América, no se han transformado en instrumentos americanistas decolonizadores, pero, vuelvo a repetirlo y por última vez aquí, constituyen materiales de reflexión necesarios en esta lectura de $E l$ Quijote desde (las) Américas, desde Chile, etc., que está en ese proceso de alcanzar una epistemología propia -cuando sepamos quiénes somos y nos proyectemos así hacia el pasado y hacia el futuro- que nos sitúe, en igualdad, como una realidad geográfica, cultural e intelectualmente coexistente -lo cual implica, necesariamente, también reconocer al interior de cada país a los pueblos indígenas que quedan como entidades de suyo nacionales en coexistencia. Lautaro Yankas proponía en su texto "Nosotros y el Quijote" (1959), de una forma cuasi interrogativa y aludiendo a la peregrinación de muchos americanos por la ruta de Don Quijote y Sancho, una tarea pendiente: ... "el hispano inspirado y el criollo de América, se han cruzado muchas veces en los caminos manchegos, sin reconocerse, acaso" (156) -así como ha sucedido, en nuestras propias rutas americanas, entre el criollo/mestizo (asimilado a la cultura dominante) de América y los habitantes originales y mestizos (insertos en las culturas dominadas). Recuérdese, con Carlos Fuentes, como se citó anteriormente, que la Mancha es América también, y Chile uno de sus recodos.

Cierto es que algunos de los conquistadores -y luego algunos de los colonizadores- pueden haber tenido, dada su ya muy indirecta educación en los secretos de la caballería, esas "cualidades quijotescas" que Don Quijote exhibiría posteriormente, pero en rigor no lo eran. Sabemos -Borges lo ha demostrado con su texto "Un problema"- que Don Quijote no podría haber matado (o, en un plano de conquista, exterminado, aunque fuera por la llamada vía de la pacificación) y seguir siendo el mismo hasta hoy. Tal como advierte Triviños sobre La Araucana (248), El Quijote no es un canto épico de vencedores; es, en cambio y si se quiere así, una especie de épica humanista, desilusionada del mito épico (que en el siglo XIX llegó a definirse, propagarse y defenderse como la "ley universal del progreso"): en aquélla, del mito (del) conquistador; en éste, del mito caballeresco (en lo que tiene de violencia hacia el otro, visto esto más desde Cervantes que desde Don Quijote como personaje), porque "[t]he satire in Don Quijote is aimed not at medieval chivalry -such a retrograde target would be quixotic- but at its early modern revivals, at the mimicry of chivalry displayed by both Don Quixote and the conquistadores" (Wilson 2000: 135).

\section{BIBLIOGRAFÍA}

Añunta, José G. Cervantes y el Quijote en tierras de América. Madrid: s/e, 1960.

Apráiz y Sáenz del Burgo, Julián de. "Cervantes y América”. Sawa, Miguel y Pablo Becerra, eds. Crónica del Centenario del "Don Quijote”. España: s/e, 1905. 314-317.

Araneda Bravo Fidel. Boletín de la Academia Chilena 63 (Santiago de Chile, 1973). En El Quijote en Chile. Introducción y selección de textos Sergio Macías. Santiago de Chile: Aguilar, 2005. 125-138. 
Arriagada Lassel, Adriana. "Imagen fabulosa de las Indias a través de Cervantes". Santiago de Chile: Ateneo, 1992.

Barahona Vega, Clemente. Cervantes en el folklore chileno. Un proyecto para la celebración del Centenario. Santiago de Chile: Imprenta San Buenaventura, 1915.

Batres Jáuregui, Antonio. "Miguel de Cervantes Saavedra en Goathemala". El castellano en América. Guatemala: Imprenta de 'La República”, 1904.

Bengoa, José. Historia del pueblo mapuche. Siglo XIX y XX. Santiago: Ediciones Sur, 1985.

Brioso Santos, Héctor [Con la colaboración de José Montero Reguera]. Cervantes y América. Madrid: Marcial Pons, Ediciones de Historia, 2006.

Césped Benítez, Irma. Para leer El Quijote. Santiago: Universidad Andrés Bello/RIL Editores, 2000.

Coronil, Fernando. "Latin American postcolonial studies and global decolonization." Lazarus, Neil, ed. The Cambridge Companion to Postcolonial Literary Studies. Cambridge, UK: Cambridge University Press, 2004.

Correa-Díaz, Luis. Cervantes y América / Cervantes en las Américas: mapa de campo y ensayo de bibliografia razonada. Kassel/Barcelona: Reichenberger Edition, 2006.

D’Halmar, Augusto. La Mancha de Don Quijote. Santiago: Editorial Ercilla, 1934.

Durand, Luis. “América y Cervantes". Atenea 268 (Octubre 1947): 5-10.

Edwards, Jorge. "La aventura del idioma”. El Quijote en Chile. Introducción y selección de textos Sergio Macías. Santiago de Chile: Aguilar, 2005. 215-222.

Eliz, Leonardo. Apuntes para una bibliografia chilena sobre Cervantes. Valparaíso: Imprenta Royal, 1916.

Epple, Juan Armando. MicroQuijotes. Barcelona: Thule Ediciones, 2005.

Eyzaguirre, Jaime. “América, meta de la caballería". Revista de Estudios 145-146 (FebreroMarzo 1945): 3-12.

Fernández, Jorge R. "Presencia de América en la obra de Cervantes". Atenea 268 (Octubre 1947): 191-205.

Fuentes, Carlos. El espejo enterrado. México: Fondo de Cultura Económica, 1992.

Hozven, Roberto. "El Quijote, Cervantes y los ensayistas chilenos". Estudios Públicos 100 (Primavera 2005): 325-336. En-línea: http://www.cepchile.cl/dms/lang_1/doc_3700.html

Lafaye, Jacques. Los conquistadores. Figuras y escrituras. México: Fondo de Cultura Económica, 1999 [1964].

Lastra, Pedro. "Don Quijote impugna a los comentadores de Cervantes por razones puramente personales". Chicago Review 27(2) (Autumn 1975): 168 (en castellano) y 169 (en inglés).

Lerner, Isaías. "América y la poesía épica áurea: la versión de Ercilla”. Edad de Oro 10 (1991): 125-140.

Lira Urquieta, Pedro. "El Quijote y nuestro lenguaje”. Boletín de la Academia Chilena correspondiente de la Real Academia Española. Tomo XV - Cuaderno XLVIII (1959): 4855.

Macías, Sergio. El Quijote en Chile. Introducción y selección de textos Sergio Macías. Santiago de Chile: Aguilar, 2005.

Mancing, Howard. The Cervantes Encyclopedia. Westport, CT/London: Greenwood Press, 2004. 
Manguel, Alberto. A History of Reading. New York: Penguin Books, 1996.

Martínez Bonati, Félix. Don Quijote and the Poetic of the Novel. Ithaca: Cornell University Press, 1992.

Medina, José Toribio. “Cervantes americanista”. Estudios cervantinos. Prólogo del Dr. Rodolfo Oroz Scheibe. Santiago de Chile: Fondo Historiográfico y Bibliográfico José Toribio Medina, 1958. 505-537.

“Cervantes en las letras chilenas". Estudios cervantinos. Prólogo del Dr. Rodolfo Oroz Scheibe. Santiago de Chile: Fondo Historiográfico y Bibliográfico José Toribio Medina, 1958. 565-598.

"Escritores americanos celebrados por Cervantes en el Canto a Calíope." Estudios cervantinos. Prólogo del Dr. Rodolfo Oroz Scheibe. Santiago: Fondo Historiográfico y Bibliográfico José Toribio Medina, 1958. 455-503. En línea: http://www. cervantesvirtual.com/servlet/SirveObras/12815959228941622423513/index.htm

Mignolo, Walter. "De-linking: Don Quixote, Globalization and the Colonies". Quixotic Offspring: The Global Legacy of Don Quixote. Macalester International, vol. 17 (Spring 2006): 3-35.

Molina, Julio. "Cervantes en Chile". Atenea 268 (Octubre 1947): 136-147.

Montero Reguera, José. “El Quijote en Hispanoamérica”. Brioso Santos, Héctor [Con la colaboración de José Montero Reguera]. Cervantes y América. Madrid: Marcial Pons, Ediciones de Historia, 2006. 317-343.

Ochoa Shipavour, Marcela. "Juan Montalvo: una reescritura del Quijote en América". Inti 46-47 (Otoño 1997-Primavera 1998): 57-69.

Reescrituras del Quijote. Santiago de Chile: LOM Ediciones, 1997.

Olea, Mario. El regreso de Alonso Quijano. Cuentos-Reflexiones-Crónicas. Santiago de Chile: CESOC, 2003.

Oses, Darío. "El Quijote de la paz”. http://www.nuestro.cl/opinion/columnas/quijotescos1. htm

Pizarro Cortés, Carolina. "El Quijote, ciudadano de América". (http://www.revistacriterio. com.ar/art_cuerpo.php?numero_id=76\&articulo_id=1560)

Poblete, Egidio [Ronquillo]. El Quijote en Chile. Chile Ilustrado 34 (Mayo 1905).

Quijano, Aníbal. "Don Quijote y los molinos de viento en América Latina”. http://www. oeiperu.org/documentos/ClavesQuijano.pdf

Rojas, Gonzalo. "Discurso [de recepción] del Premio Cervantes 2003”. El Quijote en Chile. Introducción y selección de textos Sergio Macías. Santiago de Chile: Aguilar, 2005. 267277.

Román, M. Antonio. "La lengua del Quijote y la de Chile". Homenaje a Cervantes: discursos leídos en la sesión solemne con que la Academia Chilena conmemoró, el 23 de abril de 1916, el tercer centenario de la muerte de Cervantes. Santiago de Chile: Academia Chilena de la Lengua / Imprenta Universitaria, 1916.

Rozo Rozo, Julio. Sancho Panza. Gobernador y Juez frente a la legislación colombiana. Santa Fe de Bogotá: Universidad Sergio de Arboleda, 1999.

Sander, Carlos. En busca del Quijote. Santiago de Chile: Editorial Nascimento, 1967.

Sullivan, Maurice W. "La influencia de Cervantes y de su obra en Chile". Anales Cervantinos 2 (1952): $287-310$. 
Triviños, Gilberto. "La hermosa y decisiva conquista de la Araucanía". Rodríguez, Mario y Pedro Lastra, eds. Félix Martínez Bonati. Homenaje. Concepción: Editorial Universidad de Concepción, 2003. 239-251.

Uribe-Echevarría, Juan. Cervantes en las letras hispanoamericanas (Antología y Crítica). Santiago de Chile: Ediciones de la Universidad de Chile, 1949. 395-420.

"Medina cervantista. Antecedentes". Atenea 327-328 (Septiembre-octubre 1952):

Valle, Rafael Heliodoro y Emilia Romero. Bibliografía cervantina en la América Española. México: Universidad Nacional Autónoma de México/Academia Mexicana de la Lengua, 1950.

Williamson, Edwin. "The Quixotic Roots of Magic Realism: History and Fiction from Alejo Carpentier to Gabriel García Márquez". Williamson, Edwin, ed. Cervantes and the modernists: the question of influence. London: Tamesis, 1994.

Wilson, Diana de Armas. "Cervantes and the New World". Cascardi, Anthony J., ed. The Cambridge Companion to Cervantes. Cambridge: Cambridge University Press, 2002. 206-225. 2000 .

Cervantes, the Novel, and the New World. Oxford: Oxford University Press,

“ 'De gracia estraña': Cervantes, Ercilla y el Nuevo Mundo”. Dopico Black, Georgina y Roberto González Echevarría, coords. En un lugar de La Mancha: Estudios Cervantinos en honor de Manuel Durán. Salamanca: Ediciones Almar, 1999. 37-55.

Yankas, Lautaro: "Nosotros y el Quijote”. Atenea, 134 [384] (1959), 152-156.

Palabras clave: Cervantes, El Quijote, América, Chile.

KEY WORDS: Cervantes, El Quijote, América, Chile. 